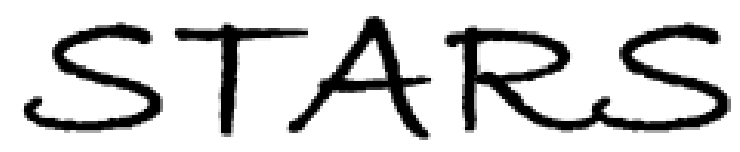

University of Central Florida

STARS

$1-1-2010$

\title{
Poly(3-hexylthiophene) crystalline nanoribbon network for organic field effect transistors
}

\author{
M. Arif \\ University of Central Florida \\ Jianhua Liu \\ University of Central Florida \\ Lei Zhai \\ University of Central Florida \\ Saiful I. Khondaker \\ University of Central Florida
}

Find similar works at: https://stars.library.ucf.edu/facultybib2010

University of Central Florida Libraries http://library.ucf.edu

This Article is brought to you for free and open access by the Faculty Bibliography at STARS. It has been accepted for inclusion in Faculty Bibliography 2010 s by an authorized administrator of STARS. For more information, please contact STARS@ucf.edu.

\section{Recommended Citation}

Arif, M.; Liu, Jianhua; Zhai, Lei; and Khondaker, Saiful I., "Poly(3-hexylthiophene) crystalline nanoribbon network for organic field effect transistors" (2010). Faculty Bibliography 2010s. 6956.

https://stars.library.ucf.edu/facultybib2010/6956

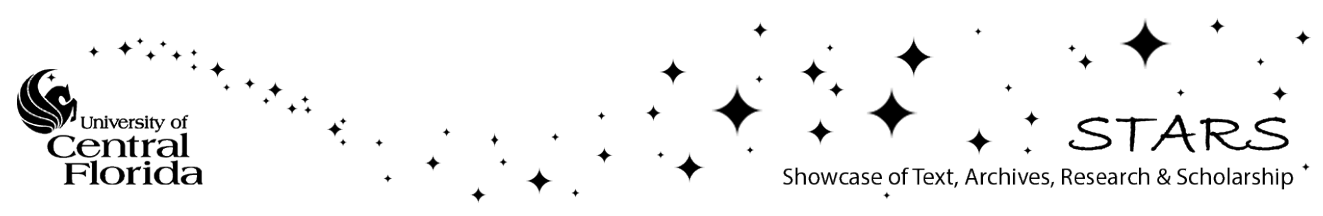




\section{Poly(3-hexylthiophene) crystalline nanoribbon network for organic field effect transistors}

Cite as: Appl. Phys. Lett. 96, 243304 (2010); https://doi.org/10.1063/1.3455097

Submitted: 13 January 2010 . Accepted: 24 May 2010 . Published Online: 16 June 2010

M. Arif, Jianhua Liu, Lei Zhai, and Saiful I. Khondaker

\section{ARTICLES YOU MAY BE INTERESTED IN}

Solubility-driven thin film structures of regioregular poly(3-hexyl thiophene) using volatile solvents

Applied Physics Letters 90, 172116 (2007); https://doi.org/10.1063/1.2734387

Soluble and processable regioregular poly(3-hexylthiophene) for thin film field-effect transistor applications with high mobility

Applied Physics Letters 69, 4108 (1996); https://doi.org/10.1063/1.117834

Thermal annealing-induced enhancement of the field-effect mobility of regioregular poly(3-hexylthiophene) films

Journal of Applied Physics 100, 114503 (2006); https://doi.org/10.1063/1.2400796

\section{Applied Physics Reviews} Now accepting original research 


\title{
Poly(3-hexylthiophene) crystalline nanoribbon network for organic field effect transistors
}

\author{
M. Arif, ${ }^{1,2}$ Jianhua Liu, ${ }^{1,3}$ Lei Zhai, ${ }^{1,3}$ and Saiful I. Khondaker ${ }^{1,2, a)}$ \\ ${ }^{1}$ Nanoscience Technology Center, University of Central Florida, Orlando, Florida 32826, USA \\ ${ }^{2}$ Department of Physics, University of Central Florida, Orlando, Florida 32826, USA \\ ${ }^{3}$ Department of Chemistry, University of Central Florida, Orlando, Florida 32826, USA
}

(Received 13 January 2010; accepted 24 May 2010; published online 16 June 2010)

\begin{abstract}
We report on the fabrication of crystalline nanoribbon network field effect transistors (FETs) using low molecular weight $\left(\mathrm{M}_{\mathrm{W}}\right)$ poly(3-hexylthiophene) (P3HT) with different surface treatments and compare with thin film FETs cast from the same $\mathrm{M}_{\mathrm{W}}$ regioregular P3HT. Nanoribbon FET shows improved performance with a maximum mobility of $0.012 \mathrm{~cm}^{2} / \mathrm{V} \mathrm{s}$ and current on/off ratios of $6.5 \times 10^{4}$ due to unique crystalline structure and morphology. With various surface treatments, the nanoribbon FETs show less variation in device mobilities, while thin film FETs show more than ten times variation in device mobilities and up to 100 times change in current on/off ratios. () 2010 American Institute of Physics. [doi:10.1063/1.3455097]
\end{abstract}

Regioregular poly(3-hexylthiophene) (rr-P3HT) is considered to be one of the most promising organic semiconductors for low cost electronic devices because of its easy solution processing and high charge carrier mobility. ${ }^{1-4}$ In order to fabricate devices with high mobility, one of the main challenges is to control the film morphology of the P3HT and the degree of crystallinity which depends on the material's intrinsic properties such as regioregularity, ${ }^{5}$ molecular weight $\left(\mathrm{M}_{\mathrm{W}}\right),{ }^{6,7}$ and molecular orientation/ordering. ${ }^{4}$ The mobility also highly depends on the processing conditions such as surface treatments, ${ }^{8,9}$ thermal treatment, ${ }^{2,6}$ and casting solvents, ${ }^{10}$ as well as deposition techniques. ${ }^{3,11}$ In particular, low $\mathrm{M}_{\mathrm{W}}$ P3HT films show larger dependence of processing conditions than high $\mathrm{M}_{\mathrm{W}}$ P3HT film. ${ }^{12}$ For example, the field effect charge carrier mobility of low $\mathrm{M}_{\mathrm{W}}(3-10 \mathrm{kD})$ P3HT could change two to four orders of magnitude with different surface treatments and casting solvents due to the changes in overall polymer crystallinity and morphology at the interface between the polymer and dielectric., 82

In order to fabricate devices with enhanced morphology for improved charge carrier transport, attention has been recently devoted toward the development of one dimensional and two dimensional (2D) crystalline nanostructures based on self-organized P3HT in the form of nanowires and nanofibers. ${ }^{13-16}$ Crystalline P3HT nanostuctures should show improved electronic properties resulting from their increased interchain staking with $\pi-\pi$ orbital overlap. Previous studies have shown that low $\mathrm{M}_{\mathrm{W}}$ P3HT film can form well defined and highly ordered nanorods depending on the processing conditions with increased in-plane $\pi$ staking along the nanorod axis. But the length of these nanorods is only about $8 \mathrm{~nm}$ and the low orientational order between small aggregates of nanorods hinders charge transport. ${ }^{6,12}$ Moreover, the mobility of the thin film of these nanorods is limited by numerous grain boundaries. It is expected that if the aspect ratio of the nanocrystalline structure could increase, it would provide enhanced charge transport with improved mobility due to fewer grain boundaries and improved morphology.

\footnotetext{
${ }^{\text {a) }}$ Author to whom correspondence should be addressed. Electronic mail: saiful@mail.ucf.edu.
}

Here we report on the fabrication and charge transport properties of high aspect ratio crystalline nanoribbon field effect transistors (FETs) using low $\mathrm{M}_{\mathrm{W}}(10.2 \mathrm{kD})$ P3HT. The devices show good transistor characteristics with saturation mobilities of up to $1.2 \times 10^{-2} \mathrm{~cm}^{2} / \mathrm{V} \mathrm{s}$ and current on/off ratios of $6.5 \times 10^{4}$. We also show that when the FETs were fabricated with different surface treatments, the charge carrier mobility is relatively insensitive due to the unique $2 \mathrm{D}$ crystalline nature of the nanoribbon. In contrast, our controlled experiment with the same $\mathrm{M}_{\mathrm{W}}$ P3HT thin film FET (not in the nanoribbon arrangement) shows ten times variation in carrier mobility and 100 times change in current on/ off ratios with similar surface treatments.

The nanoribbons have been fabricated from P3HT (10.2 $\mathrm{kD})$ using a solution method following our recently developed technique. ${ }^{17}$ In brief, P3HT was first dissolved into anisole at $90{ }^{\circ} \mathrm{C}$ with a concentration of $0.25 \mathrm{mg} / \mathrm{mL}$ in a glass vial. The solution was then incubated in a water bath at $25^{\circ} \mathrm{C}$ for $12 \mathrm{~h}$ to form the nanoribbon dispersion. Figure 1(a) shows a transmission electron microscope (TEM) image of as fabricated P3HT nanoribbons. From the TEM image,

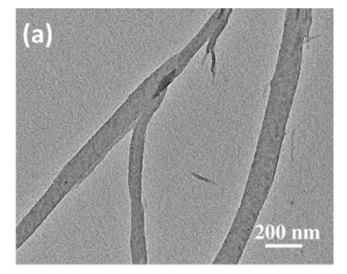

(c)

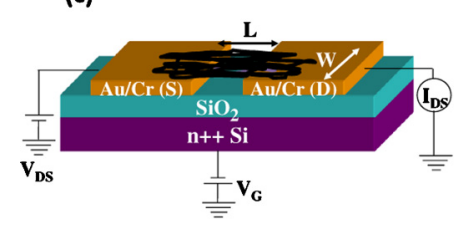

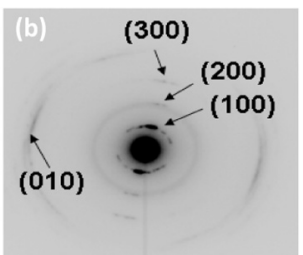

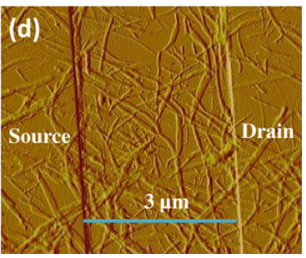

FIG. 1. (Color online) (a) TEM image of the P3HT nanoribbon with width 50-200 nm. (b) Selective area electron diffraction pattern of P3HT nanoribbon. (c) Schematic of device structure and transport measurement setup and (d) AFM image of P3HT nanoribbon network between source and drain electrodes. 
the width of the nanoribbon was found to be 50-200 $\mathrm{nm}$ and length varied from 3 to $5 \mu \mathrm{m}$, giving a maximum aspect ratio of 100 . The thickness of the nanoribbon varied between $15-17 \mathrm{~nm}$ as measured by tapping mode atomic force microscopy (AFM). Figure 1(b) shows the selective area electron diffraction pattern of the nanoribbons which indicates their 2D crystalline nature.

FETs were fabricated in the bottom-gate, bottom-contact configuration on heavily doped n-type Si substrates with a $250 \mathrm{~nm}$ capped layer of $\mathrm{SiO}_{2}$. Source and drain electrodes were defined using double layer photolithography (LOR 3A/ Shipley 1813) developing in CD26, followed by thermal evaporation of chromium $(\mathrm{Cr})(3 \mathrm{~nm})$ and gold $(\mathrm{Au})(45 \mathrm{~nm})$ and finally standard lift-off. The channel length (L) and channel width (W) were $3 \mu \mathrm{m}$ and $200 \mu \mathrm{m}$, respectively. The devices were cleaned in acetone and isopropanol, respectively, for $5 \mathrm{~min}$ each and then exposed to $\mathrm{O}_{2}$ plasma for 10 min before an ethanol wash. Three types of FET devices were fabricated with different surface treatments. The first device was only $\mathrm{O}_{2}$ plasma treated and is referred to as untreated sample. In the other two devices after exposing to $\mathrm{O}_{2}$ plasma, two types of silane molecules were deposited on the substrate, (1) octyltrichlorosilane (OTS) and (2) hexamethyldisilazane (HMDS), to form self-assembled monolayer (SAM). After the surface treatment, all the devices were fabricated by drop casting $(0.25 \mathrm{mg} / \mathrm{mL})$ P3HT nanoribbon dispersion inside a $\mathrm{N}_{2}$ glove box. The fabricated devices were then thermally annealed at $140{ }^{\circ} \mathrm{C}$ on a hotplate for $15 \mathrm{~min}$ to evaporate the solvent. Figure 1(c) schematically shows the device structure with transport measurement set up and Fig. 1(d) shows the AFM image of one of our devices taken after electrical transport measurements. It can be seen from the AFM image that the electrodes are connected by many individual P3HT nanoribbons making a network FET. The current-voltage characteristics of the FET were measured using Hewlett Packard (HP) 4145 B semiconductor parametric analyzer in an enclosed glove box system with $\mathrm{N}_{2}$ flow.

Figure 2(a) shows the source-drain current $\left(\mathrm{I}_{\mathrm{DS}}\right)$ versus source-drain voltage $\left(\mathrm{V}_{\mathrm{DS}}\right)$ characteristics of the HMDS treated P3HT nanoribbon FETs measured at different gate voltages $\left(\mathrm{V}_{\mathrm{G}}\right)$ from 0 to $-80 \mathrm{~V}(20 \mathrm{~V}$ intervals). The device exhibits well defined p-type behavior in accumulation mode. Figure 2(b) shows the transfer characteristics $\left(\mathrm{I}_{\mathrm{DS}}-\mathrm{V}_{\mathrm{G}}\right)$ at fixed $\mathrm{V}_{\mathrm{DS}}=-60 \mathrm{~V}$, represented in the left vertical axis of the graph. The right vertical axis of the graph shows $\sqrt{\mathrm{I}_{\mathrm{DS}}}$ as a function of $\mathrm{V}_{\mathrm{G}}$. The field effect mobility $\mu$ is determined from the saturation regime using the relationship between $\mathrm{I}_{\mathrm{DS}}$ and $\mathrm{V}_{\mathrm{G}}$ from the equation $\mathrm{I}_{\mathrm{DS}}=\left(\mathrm{W} C_{i} / 2 \mathrm{~L}\right) \mu\left(\mathrm{V}_{\mathrm{G}}-\mathrm{V}_{\mathrm{T}}\right)^{2}$, where $\mathrm{V}_{\mathrm{T}}$ is the threshold voltage; $C_{i}$ is the capacitance/unit area of the oxide layer $\left(13.8 \mathrm{nF} / \mathrm{cm}^{2}\right)$. From the plot, the saturation mobility was calculated to be $0.012 \mathrm{~cm}^{2} / \mathrm{V} \mathrm{s}$ and current on/off ratio was $6.5 \times 10^{4}$.

Figure 3(a) shows the output characteristics of our P3HT nanoribbon FETs at different $\mathrm{V}_{\mathrm{G}}$ for various surface treatments. All the devices show excellent gate modulation and current saturation. Figure 3(b) represents transfer characteristics at $V_{D S}=-60 \mathrm{~V}$ and Fig. 3(c) shows $\sqrt{I_{D S}}$ as a function of $\mathrm{V}_{\mathrm{G}}$ for the same samples in the saturation regime. It can be seen from these figures that the surface treatments have a negligible influence on the device properties. The maximum charge carrier mobility was calculated from the saturation regime. The HMDS treated sample shows mobility of 1.2
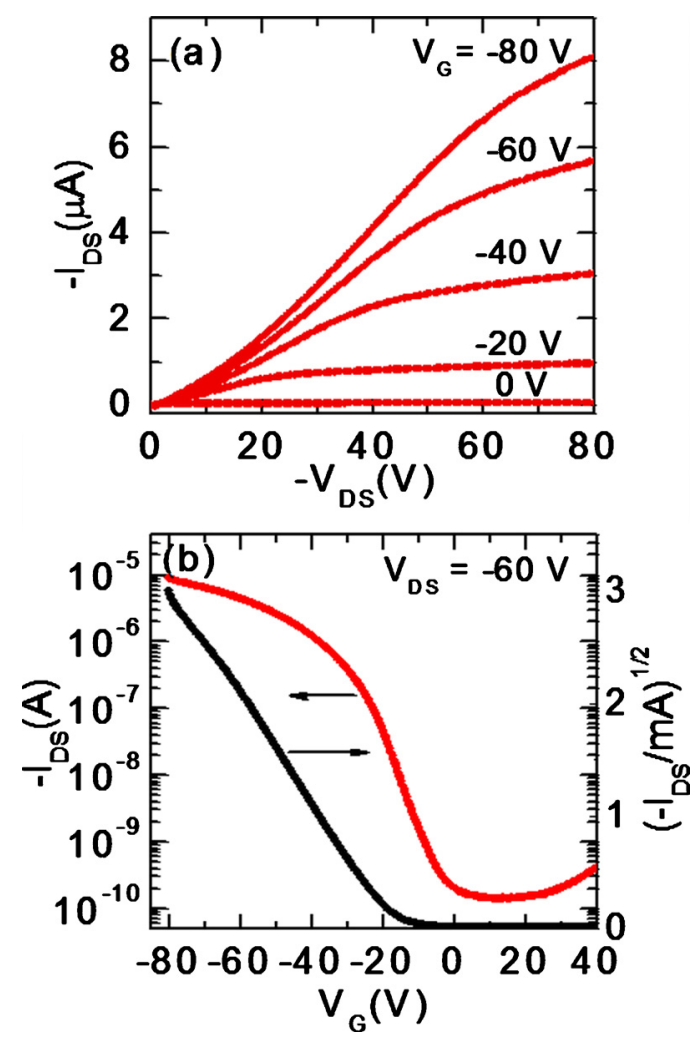

FIG. 2. (Color online) (a) Output characteristics with HMDS treated P3HT nanoribbon FET for $\mathrm{L}=3 \mu \mathrm{m}$ and $\mathrm{W}=200 \mu \mathrm{m}$ and (b) transfer characteristics of the device measured at fixed $V_{D S}=-60 \mathrm{~V}$ (left axis) and $\sqrt{\mathrm{I}_{\mathrm{DS}}}$ in the saturation regime as a function of $\mathrm{V}_{\mathrm{G}}$ (right axis).

$\times 10^{-2} \mathrm{~cm}^{2} / \mathrm{V} \mathrm{s}$ while the OTS treated and untreated samples show mobilities of $5.5 \times 10^{-3} \mathrm{~cm}^{2} / \mathrm{V} \mathrm{s}$ and 7.8 $\times 10^{-3} \mathrm{~cm}^{2} / \mathrm{V}$ s, respectively. Also the current on/off ratios of these three samples are in the same order and varies from $2.0 \times 10^{4}$ to $6.5 \times 10^{4}$. The maximum variation in mobility and current on/off ratios with different surface treatments is about 3 times. The lessened effect of surface treatments and improved performance in the nanoribbon FETs are due to the presence of unique crystalline structures with well-defined morphology at the dielectric and polymer interface. There-
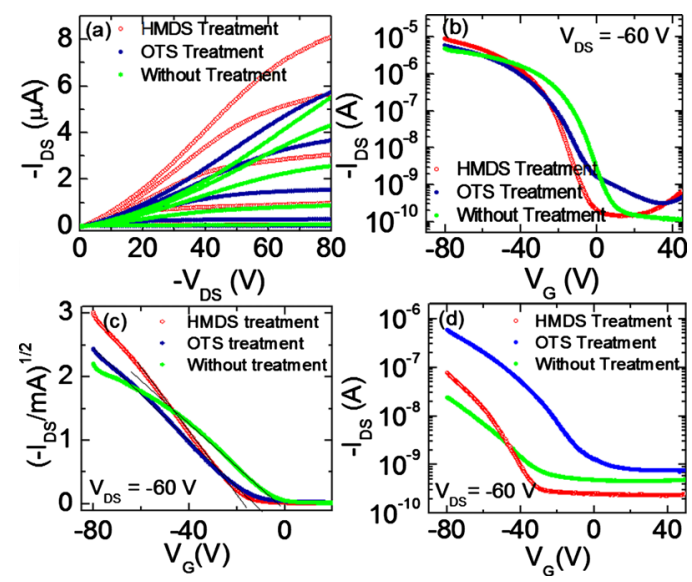

FIG. 3. (Color online) Output and transfer characteristics of FETs fabricated from P3HT nanoribbon network with different surface treatments. (a) Output characteristics of the device at different $\mathrm{V}_{\mathrm{G}}$, (b) transfer characteristics measured at fixed $V_{D S}=-60 \mathrm{~V}$ and (c) $\sqrt{\mathrm{I}_{\mathrm{DS}}}$ in the saturation regime as a function of $\mathrm{V}_{\mathrm{G}}$, and (d) transfer characteristics of controlled low $\mathrm{M}_{\mathrm{W}}$ P3HT polymer FETs. 

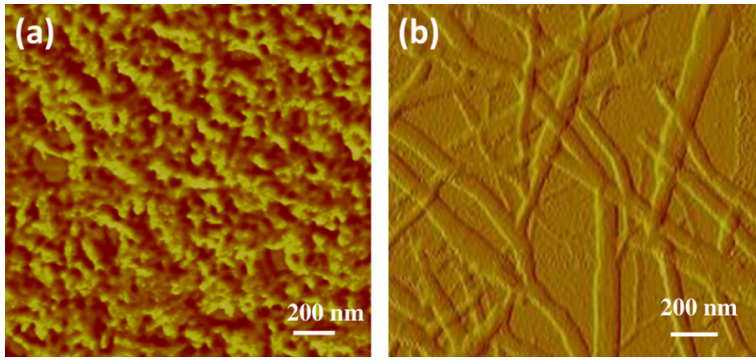

FIG. 4. (Color online) (a) AFM image of low $\mathrm{M}_{\mathrm{W}}$ P3HT film and (b) AFM image of P3HT nanoribbon network showing less grain boundaries and large crystal for better charge transport.

fore, the surface treatments cannot further enhance the morphology. Nevertheless, small changes in mobility in different devices for various treatments could be attributed to a small variation in contact resistance. In order to find out whether thermal annealing has effect on recrystallization of the P3HT nanoribbon FET devices, we have performed a controlled experiment to measure the mobility before and after thermal annealing with same surface treatment condition. We have found that there is negligible variation in the mobility of the P3HT nanoribbon FETs indicating that there is no further crystallization due to annealing.

In order to further understand the quality of our nanoribbon FET devices and for a fair comparison of the mobility, we fabricated thin film FETs with similar surface treatments drop cast from the solution of the same $\mathrm{M}_{\mathrm{W}}$ P3HT dissolved in chloroform and having same concentration $(0.25 \mathrm{mg} / \mathrm{mL})$ as nanoribbon. This is shown in Fig. 3(d), where we plot $\mathrm{I}_{\mathrm{DS}}$ values at fixed $\mathrm{V}_{\mathrm{DS}}=-60 \mathrm{~V}$ as a function of $\mathrm{V}_{\mathrm{G}}$. From the figure it is evident that the devices show a significant change in $\mathrm{I}_{\mathrm{DS}}$ with surface treatments. The field effect mobility calculated from saturation regime of these devices varied between $2 \times 10^{-4}$ to $1.75 \times 10^{-3} \mathrm{~cm}^{2} / \mathrm{V} \mathrm{s}$ while current on/off ratios changed from 10 to $10^{3}$ with different surface treatments and is consistent with other reports on low $\mathrm{M}_{\mathrm{W}}$ P3HT films. ${ }^{6,7,11,12}$ With surface treatments, the mobility variation is upto ten times and current on/off ratio variation is up to 100 times. In addition, the mobility values are at least ten times lower while the current on/off ratios are 1000 times lower compared to that of the nanoribbon P3HT devices reported here. It should be noted that the mobility values reported in our work is based on a network of nanoribbon structure and our preliminary studies show that the mobility of single nanoribbon FETs is as high as $0.07 \mathrm{~cm}^{2} / \mathrm{V} \mathrm{s}$. The details of this study will be published elsewhere.

To understand the reason for the improved mobility in our nanoribbon network devices, we have studied the surface morphology of the nanoribbon network film and pristine P3HT thin film from AFM images. Figure 4(a) represents the AFM image of low $\mathrm{M}_{\mathrm{W}}$ P3HT film drop cast from chloroform. The film morphology indicates the presence of small nanorods with numerous grain boundaries. Although, films cast from low $\mathrm{M}_{\mathrm{W}}$ P3HT shows crystalline order consisting of nanorods in amorphous matrix but due to its shorter chain length it shows low charge carrier mobility. The twisted disorder type crystalline structure can trap charge carrier and reduce the mobility. ${ }^{12}$ In contrast, Fig. 4(b) shows the AFM image of P3HT nanoribbon network film consisting of larger 2D crystalline structures with better ordering and less grain boundaries for improved charge transport.

In summary, we have fabricated and studied the charge transport properties of low $\mathrm{M}_{\mathrm{W}}$ crystalline P3HT nanoribbon network FETs. Devices fabricated from a network of nanoribbons using a dropcast method in bottom contact geometry with different surface treatments show p-type behavior with a maximum saturation mobility of $1.2 \times 10^{-2} \mathrm{~cm}^{2} / \mathrm{V} \mathrm{s}$ and current on/off ratios of $6.5 \times 10^{4}$. The surface treatments have less influence on charge carrier mobility and current on/off ratios, indicating the presence of a high level of structural perfection of oriented crystal at the nanoribbon dielectric interface. Also, the performance of nanoribbon network devices is much better than that of the same $\mathrm{M}_{\mathrm{W}}$ P3HT polymer film devices with similar surface treatments. Our results from these studies will contribute in potential applications of P3HT nanoribbon for organic nanoelectronics.

This work is partially supported by U.S. National Science Foundation under Grant No. ECCS 0801924 to S.I.K. and under Grant No. DMR 0746499 to L.Z.

${ }^{1}$ H. Sirringhaus, N. Tessler, and R. H. Friend, Science 280, 1741 (1998).

${ }^{2}$ S. Cho, K. Lee, J. Yuen, G. Wang, D. Moses, A. J. Heeger, M. Surin, and R. Lazzaroni, J. Appl. Phys. 100, 114503 (2006).

${ }^{3}$ G. Wang, J. Swensen, D. Moses, and A. J. Heeger, J. Appl. Phys. 93, 6137 (2003).

${ }^{4}$ D. H. Kim, Y. D. Park, Y. Jang, H. Yang, Y. H. Kim, J. I. Han, D. G. Moon, S. Park, T. Chang, C. Chang, M. Joo, C. Y. Ryu, and K. Cho, Adv. Funct. Mater. 15, 77 (2005).

${ }^{5}$ H. Sirringhaus, P. J. Brown, R. H. Friend, M. M. Nielsen, K. Bechgaard, B. M. W. Langeveld-Voss, A. J. H. Spiering, R. A. J. Janssen, E. W Meijer, P. Herwig, and D. M. de Leeuw, Nature (London) 401, 685 (1999).

${ }^{6}$ A. Zen, J. Pflaum, S. Hirschmann, W. Zhuang, F. Jaiser, U. Asawapirom, J. P. Rabe, U. Scherf, and D. Neher, Adv. Funct. Mater. 14, 757 (2004).

${ }^{7}$ R. J. Kline, M. D. McGehee, E. N. Kadnikova, J. Liu, and J. M. J. Fréchet, Adv. Mater. 15, 1519 (2003)

${ }^{8}$ R. J. Kline, M. D. McGehee, and M. F. Toney, Nature Mater. 5, 222 (2006).

${ }^{9}$ Y. D. Park, J. A. Lim, H. S. Lee, and K. Cho, Mater. Today 10, 46 (2007).

${ }^{10}$ J. F. Chang, B. Sun, D. W. Breiby, M. M. Nielsen, T. I. Sölling, M. Giles, I. McCulloch, and H. Sirringhaus, Chem. Mater. 16, 4772 (2004).

${ }^{11}$ J. M. Verilhac, G. L. Blevennec, D. Djurado, F. Rieutord, M. Chouiki, J. P. Travers, and A. Pron, Synth. Met. 156, 815 (2006).

${ }^{12}$ R. J. Kline, M. D. McGehee, E. N. Kadnikova, J. Liu, J. M. J. Fréchet, and M.F. Toney, Macromolecules 38, 3312 (2005).

${ }^{13}$ D. H. Kim, J. T. Han, Y. D. Park, Y. Jang, J. H. Cho, M. Hwang, and K. Cho, Adv. Mater. 18, 719 (2006).

${ }^{14}$ D. H. Kim, Y. Jang, Y. D. Park, and K. Cho, J. Phys. Chem. B 110, 15763 (2006).

${ }^{15}$ J. A. Merlo and C. D. Frisbie, J. Phys. Chem. B 108, 19169 (2004).

${ }^{16}$ R. Zhang, B. Li, M. C. Iovu, M. Jeffries-EL, G. Sauve, J. Cooper, S. Jia, S. Tristram-Nagle, D. M. Smilgies, D.N. Lambeth, R.D. McCullough, and T. Kowalewski, J. Am. Chem. Soc. 128, 3480 (2006).

${ }^{17}$ J. Liu, M. Arif, J. Zou, S. I. Khondaker, and L. Zhai, Macromolecules 42, 9390 (2009). 